\title{
Is faster better?
}

\section{Towards development of} quick-growing jute

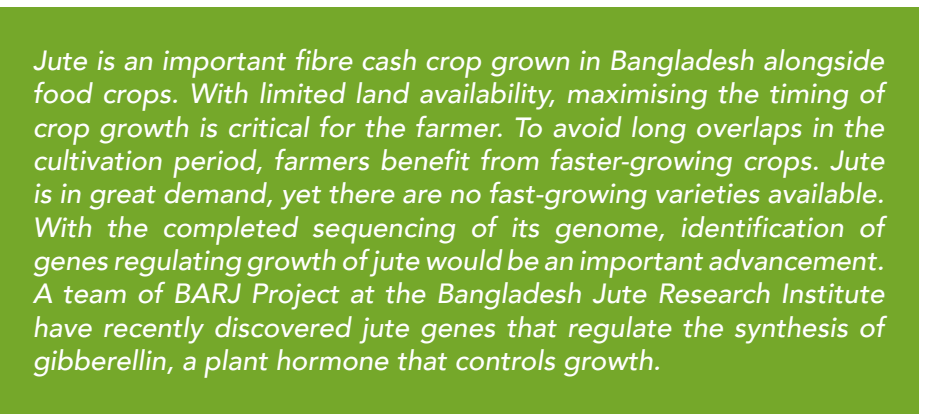

n agriculture, cash crops include rice take overlapping times to grow those plants that are grown as (up to five months), the timings of
raw materials for manufacturing growing these crops on limited land raw materials for manufacturing growing these crops on limited land
industries. Jute is one such puts intense financial pressures on industries. Jute is one such puts intense financial pressures on
important cash crop that is grown in the farmer. The solution might lie important cash crop that is grown in the farmer. The solution might lie
tropical countries for its bast fibre, in cultivating quick-growing crops tropical countries for its bast fibre, in cultivating quick-growing crops whose wide-ranging properties with shorter life cycles. With jute, everyday lives. In Bangladesh, jute that there are only two cultivated is grown alongside food crops such varieties. However, with advances in as rice in areas where land usage genome sequencing identification is constrained. Given that jute and of growth-related genes makes it

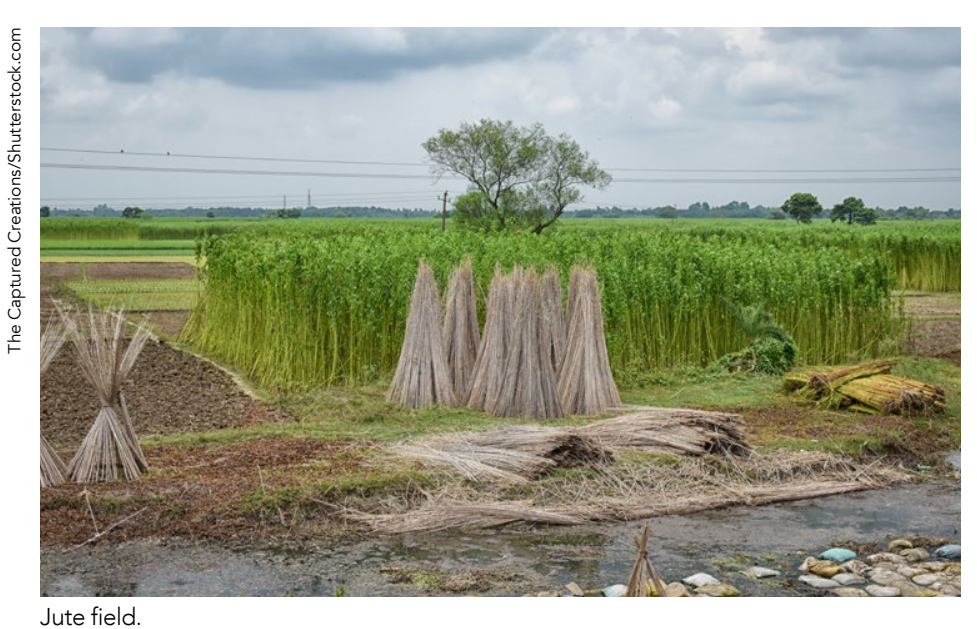

possible to generate quick-growing jute. A team of BARJ Project at the Bangladesh Jute Research Institute have recently identified genes in the biosynthetic pathway of the

\section{HORMONES HELP}

Plants cannot move from place to place, so they are able to sense and respond to their environment in special ways. For example, plants can sense light, gravity, touch, and attack by other organisms, to name a few stimuli. They do this calles called hormones within their cells, amall as messengers in very produce hormones to control their behavio hormones that affect their general functioning In order to respond to the stimuli, the hormones move between cells to transmit the signal, so that the corresponding tissues can respond. For example, when light is perceived by the stem, a hormone is produced by cells on one side that causes unequal cell growth, and therefore bending of the stem towards the light source.

There are five different types of plant hormones involved develiferent growth and of these hormones operate via special chemical pathways in plant cells, resulting in specific responses at the cellular, tissue and organ levels. Plant hormones control nearly every physiologica response in plants, ranging from flowering, fruit ripening, seed germination, responses to pathogens, drought, and even ageing. Almost always, each plant response is controlled by more than one hormone, via multiple verlapping chenical pathways.

Production of plant hormones occurs are produced in active growing regions of the plant, before the cells develop specialised functions. The cells that produce the hormones contain specific genes that regulate the synthesis of each hormone. The genes encode information that results in the production of specific proteins, which in turn function processes that result in

\section{THE KEY TO GROWTH}

\section{IS GIBBERELLIN}

ury ago, Japanese scientists discovered a hormone produced by the fungus Gibberella fujikorai that infected rice plants and caused abnormal growth. was later discovered that plants also produced this hormone, named gibberellin (GA). There are more than 100 types of GAs identified from plants, bacteria and ungi, yet there are only four that re biologically active.

GAs regulate a wide variety of plant processes, including seed plant processes, wide valing seed development and ageing of

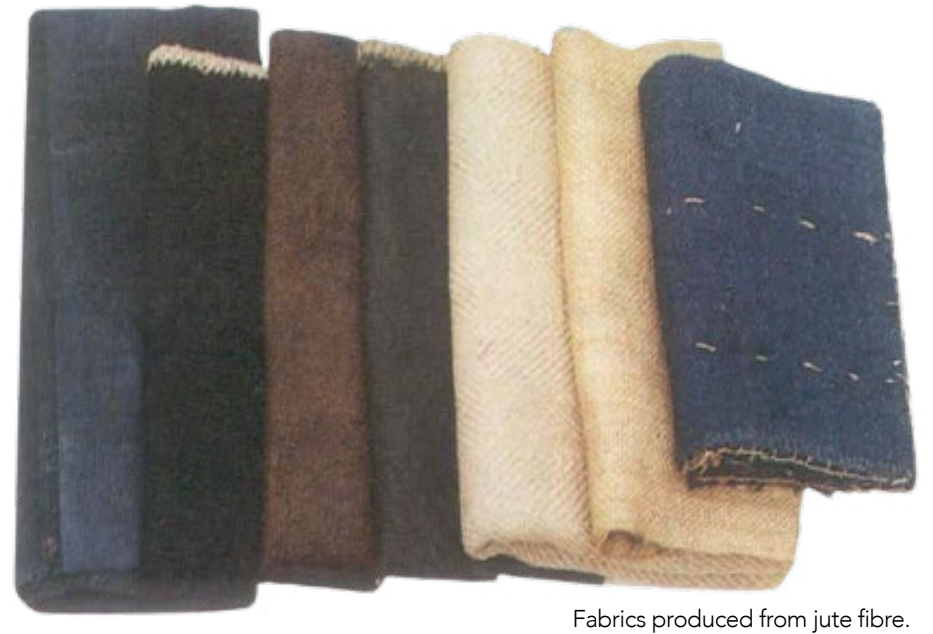

main principle that helped the Green Revolution in the 1960s the discovery of gibberellin biosynthesis genes led to the of crops that did not fall over but resulted in high yield of grains. Therefore, knowledge of genes that regulate GA biosynthesis would also advance breeding techniques in cash crops such as jute, so that the best growth rate

The GA biosynthetic pathway can be dividedinto ealy and late steps. Both of these steps have distinct enzymes that control the step-wise production of GA. The enzymes (which are proteins) control the conversion of one chemical to Fabrics produced from jute fibre. another, ultimately leading to the 


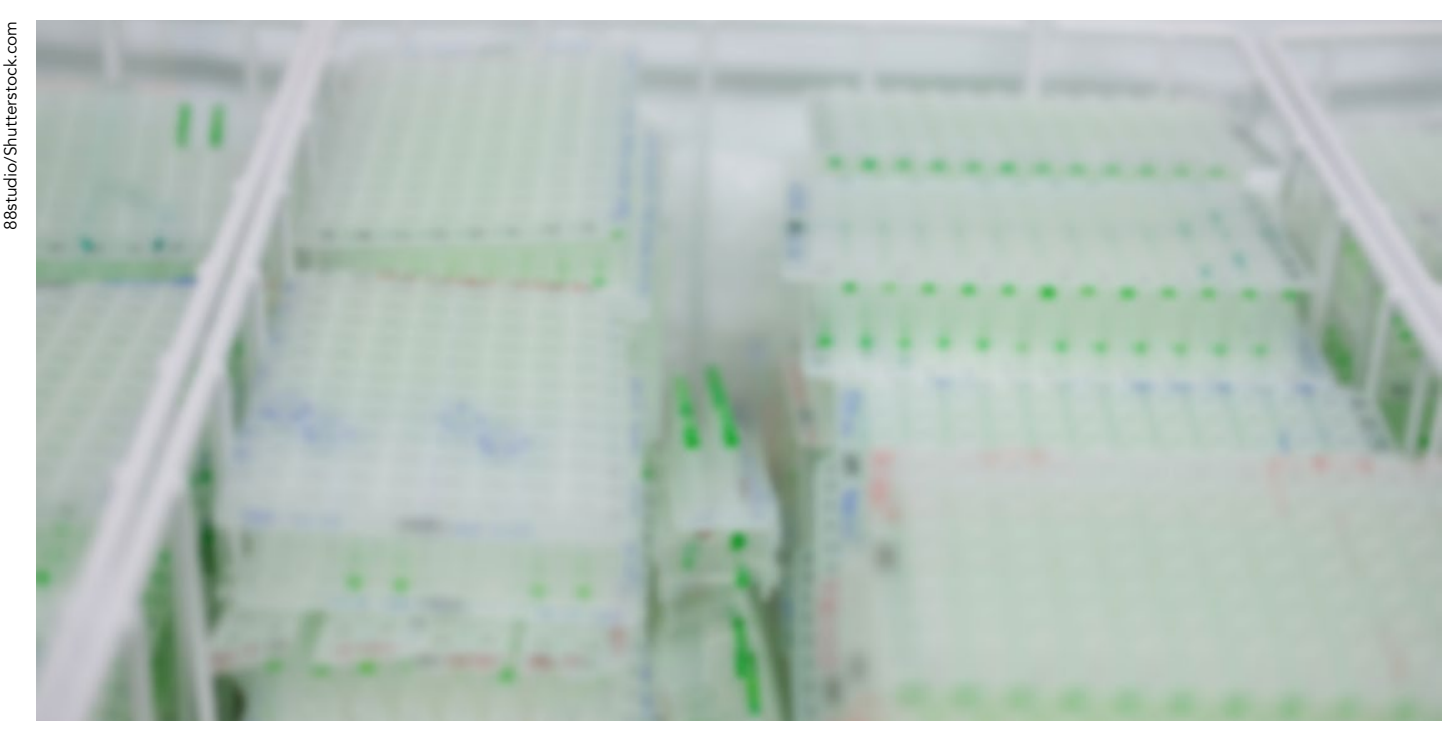

BARJ Project performed jute genome sequencing of both tossa and white jute, which involved decoding of all the genes that are

formation of biologically active GAs. The late steps are more important than the early steps to synthesise the GA biosynthetic enzymes have been identified in several plant species, but in jute this has not been possible until now because of th lack of sequence information.

REACHING GOLDEN HEIGHTS Jute, otherwise known as the golden fibre, yields fibres that are variety of uses, due to it being due to it being friendly. There are Only two species
of jute that are widely cultivated. Of these, there is no quick-growing

no identification of genes related to GA metabolism in jute. A team
of BARJ Project at the Bangladesh Jute Research Institute have recently studied how GA affects growth of jute plants and identified genes in the GA biosynthetic pathway.

\section{GROWING GENES}

In recent research by Honi et al. (2020), the effects of external spraying of GA and an inhibitor of on the growth of jute plants. The Given that GA regulates stem longation and therefore plan height, the researchers set out to identify genes involved in the GA biosynthetic pathway in jute. Using the sequenced jute genome, they queried the gene database using already known GA biosynthetic genes from other plant species. They thus identified 22 genes from jute involved in the early (four genes) and late (18 genes) steps Further work to identify where these genes are expressed (i.e., messages that make proteins) revealed that only some of these genes were expressed in the top help farmers hasten the grow period of the crop to maximise lan usage. With the recent sequencing of the jute genome, there is now vast resource ofreon ation avallable choosing traits based on genes that control them Given that GA controls growth rates of plants, it would be obvious to test the effects of $G A$ or manipulate genes related to $G A$ biosynthesis, to hasten the growth of jute. However, there has been identifying these key grow

regulatory genes, the authors have growing varieties of jute.

team found that spraying GA increased plant height by increasing the number of nodes (where leaves join to stems) and length nodes). In addition, treatment with paclobutrazol reduced plant height, thereby showing that changing the amount of GA in jute plants altered stem lengths. This was an incentive to identify genes regulating GA biosynthesis, so that quick-growing jute varieties could be bred.
By identifying these key growth regulatory genes, the authors hreed quick growing varieties to ute. Altering the amounts of these genes would enable the quantity of $G A$ to change, thereby affecting how fast the jute plant would grow. This would facilitate better usage of the limited land available to farmers. growing regions of the plant.
Research Objectives

To develop a quick growing jute variety which will reach its optimum height (3-4 metres) 20-30 days earlier

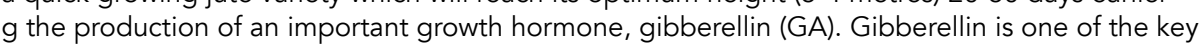
odurs of plant growth and development.

\section{References}

Honi, U., Amin, M.R., Kabir, S.M.T., et al. (2020) Genome-wide identification, characterization and expression profiling of gibberellin metabolism genes in jute. BMC Plant Biology, 20, 306. https://doi.org/10.1186/s12870$\underline{020-02512-2}$

\section{Personal Response}

Given that gibberellin also regulates flowering and seed development, how would manipulating the growth of jute plants affect yield?

II As gibberellin is an important phytohormone which cross talks with many other pathways to conduct different physiological processes of plants it's really difficult to predict the effects of manipulating endogenous GA quantity. Having said that, as jute is a bast fibre its yield actually depends on its vegetative growth that means bark length and thickness. Juts plantwith increased GA content will have a longer stem and internode. Therefore, it is expected

\section{Is it more economical to spray jute plants with gibberellin, or to generate new varieties of jute?}

II Spraying is not a sustainable solution, it will require the same spraying cost every year whereas once a transgenic plant is developed it will never require any external treatment. So as a whole, generating a new variety

\section{BARJ Jbiri \\ Basic \& Applied Research on Jute \\ Basic Aplied Research on Jute}
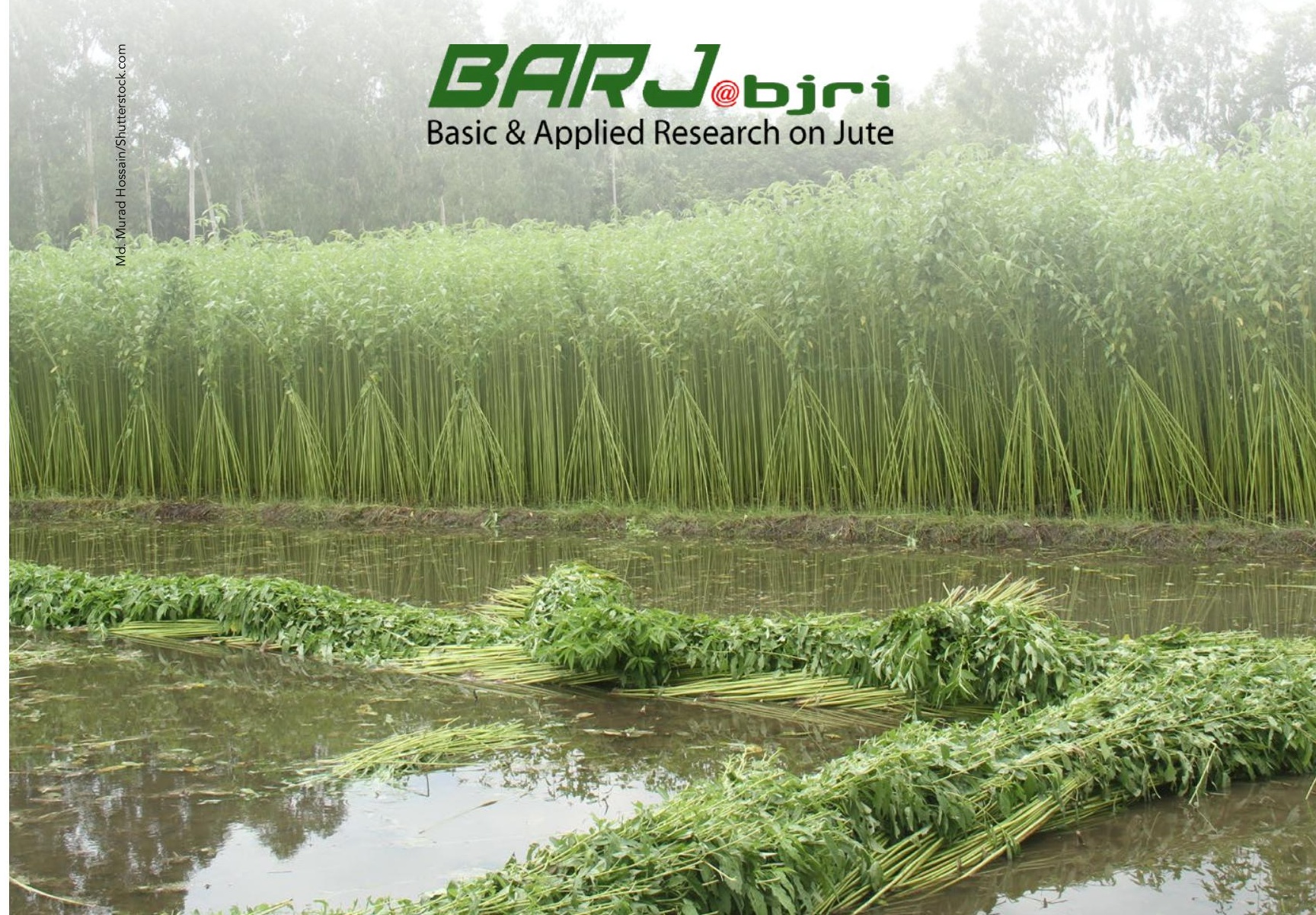